\title{
AS AÇÕES DE EXTENSÃO E CULTURA NA UNIVERSIDADE ESTADUAL DO NORTE DO PARANÁ, 2014 A 2017
}

\author{
Simone C. Castanho S. de Melo \\ Universidade Estadual do Norte doParaná \\ simonecastanho@uenp.edu.br \\ Flávia Teixeira Ribeiro da Silva \\ Universidade Estadual do Norte do Paraná \\ flavia@uenp.edu.br \\ Rui Gonçalves Marques Elias \\ Universidade Estadual do Norte doParaná \\ rgmelias@uenp.edu.br \\ James Rios de Oliveira Santos \\ Universidade Estadual do Norte doParaná \\ james@uenp.edu.br \\ Alexander Gonçalves \\ Universidade Estadual do Norte doParaná \\ alexandergolcalves@uenp.edu.br
}

\begin{abstract}
Resumo
A extensão universitária, ao longo dos últimos anos, tem passado por um processo de afirmação e consolidação dentro das Instituições de Ensino Superior (IES). Inserida neste contexto, as ações de extensão e cultura, na Universidade Estadual do Norte do Paraná, são planejadas, executadas e controladas pela Pró- Reitoria de Extensão e Cultura (PROEC). Objetivo: Desse modo, este artigo visa apresentar as ações de extensão desenvolvidas na UENP entre 2014 e 2017. Metodologia: Os dados foram levantados por meio do Sistema de Registro de Atividades de Pesquisa, Extensão e Ensino (SECAPEE) e, também, por dados obtidos através da Pró-Reitoria de Administração e Finanças (PROAF). Resultados: Ações executadas por docentes da UENP: Projetos/programas de extensão: 2014: 70; 2015: 64; 2016: 59 e 2017: 79. Eventos de extensão: 2014: 31; 2015: 34; 2016: 50 e 2017: 59. Cursos de extensão: 2014: 16; 2015: 12; 2016: 15; 2017: 20. No mesmo período, a PROEC realizou as seguintes ações culturais: Colóquios e Seminários: 04; Exposições de Artes Visuais e Exposições Literárias: 10; Mostra de Artes Cênicas: 04; Café Cultural: 02; Projetos Internacionais (Intercâmbio Cultural das Artes): 01; Oficinas Culturais: 04; Mostras e Recitais Musicais: 02; Agendamento de Apresentações em eventos:10; Apoio Cultural Interinstitucional: 06; Apoio Cultural Institucional: 08; Aprovação de Projeto em Lei de Incentivo à Cultura: 01; Projeto Cultural Institucional (UENP Talentos): 01. Atualmente, a UENP financia parte de suas ações de extensão com recursos oriundos dos seguintes órgãos para desenvolver suas ações de extensão: Fundação Araucária; Fundo Paraná; MEC e Ministério do Esporte. Conclusão: A prática de atividade de extensão, no âmbito da UENP, tem se tornado uma realidade cada vez mais concreta, uma vez que esta Instituição e a sociedade possuem vínculos viscerais. Por isso, a UENP pretende não apenas ir ao encontro das demandas da sociedade e com ela dialogar, mas, antes de tudo, ser um elemento de construção e transformação da realidade regional.
\end{abstract}

Palavras-chave: Extensão. Cultura. Recurso Financeiro. 


\title{
THE EXTENSION AND CULTURE ACTIONS AT THE STATE UNIVERSITY OF NORTH OF PARANÁ, 2014 TO 2017
}

\begin{abstract}
University extension over the last years has undergone a process of affirmation and consolidation within the Institutions of Higher Education (IES). Included in this context, the extension and culture actions at the State University of Northern Paraná are planned, executed and controlled by the Pro-Rectory of Extension and Culture (PROEC). Objective: This article aims to present the extension actions developed in UENP between 2014 and 2017. Methodology: Data were collected through the System of Registration of Research, Extension and Teaching Activities (SECAPEE) and also by data obtained through the Pro- Rectory of Administration and Finance (PROAF). Results: Actions carried out by UENP professors: Extension projects/programs: 2014: 70; 2015: 64; 2016: 59; 2017: 79. Extension events: 2014: 31; 2015: 34; 2016: 50; 2017: 59. Extension courses: 2014: 16; 2015: 12; 2016: 15; 2017: 20. In the same period, PROEC carried out the following cultural actions: Colloquiums and Seminars: 04; Exhibitions of Visual Arts and Literary Exhibitions: 10; Performing Arts Show: 04; Cultural Cafe: 02; International Projects (Cultural Exchange of Arts): 01; Cultural Workshops: 04; Musical Shows and Recitals: 02; Scheduling of Presentations in events: 10; Inter-Institutional Cultural Support: 06; Institutional Cultural Support: 08; Culture Incentive Law Project Approval: 01; Institutional Cultural Project (UENP Talentos): 01. Currently, UENP finances part of its extension actions with resources from the following organizations to develop its extension actions: Araucária Foundation; Paraná Fund; MEC; and the Ministry of Sport. Conclusion: The practice of extension activity within UENP has become an increasingly concrete reality, since this institution and society have visceral links. Therefore, UENP aims not only to meet the demands of society and to dialogue with it, but above all, to be an element of construction and transformation of the regional reality.
\end{abstract}

Key-words: Extension. Culture. Financial Resource.

\section{LAS ACCIONES DE EXTENSIÓN Y CULTURA EN LA UNIVERSIDAD ESTADUAL DEL NORTE DEL PARANÁ, 2014 A 2017}

\section{Resumen}

La extensión universitaria, a lo largo de los últimos años, ha pasado por un proceso de afirmación y consolidación dentro de las Instituciones de Enseñanza Superior (IES). En este contexto, las acciones de extensión y cultura, en la Universidad Estatal del Norte de Paraná, son planificadas, ejecutadas y controladas por la Pro-Rectoría de Extensión y Cultura (PROEC). El objetivo de este artículo es presentar las acciones de extensión desarrolladas en la UENP entre 2014 y 2017. Metodología: Los datos fueron levantados por medio del Sistema de Registro de Actividades de Investigación, Extensión y Enseñanza (SECAPEE) y, también, por datos obtenidos a través de la Pro-Rectoría de Administración y Finanzas (PROAF). Resultados: Acciones ejecutadas por docentes de la UENP: Proyectos / programas de extensión: 2014: 70; 2015: 64; 2016: 59 y 2017: 79. Eventos de extensión: 2014: 31; 2015: 34; 2016: 50 y 2017: 59.

Cursos de extensión: 2014: 16; 2015: 12; 2016: 15; 2017: 20. En el mismo período, PROEC realizó las siguientes acciones culturales: Coloquios y Seminarios: 04; Exposiciones de Artes Visuales y Exposiciones Literarias: 10; Muestra de Artes Escénicas: 04; Café Cultural: 02; Proyectos Internacionales (Intercambio Cultural de las Artes): 01; Talleres Culturales: 04; Muestras y Recitales Musicales: 02; Programación de presentaciones en eventos: 10; Apoyo Cultural Interinstitucional: 06; Apoyo Cultural Institucional: 08; Aprobación de Proyecto en Ley de Incentivo a la Cultura: 01; (UENP Talentos): 01. Actualmente, la UENP financia parte de sus acciones de extensión con recursos provenientes de los siguientes órganos para desarrollar sus acciones de extensión: Fundación Araucária; Fondo Paraná; MEC y Ministerio del Deporte. Conclusión: La práctica de actividad de extensión, en el ámbito de la UENP, se ha vuelto una realidad cada vez más concreta, una vez que esta Institución y la sociedad poseen vínculos viscerales. Por eso, la UENP pretende no sólo ir al encuentro de las demandas de la sociedad y

Cidadania em Ação: Revistade Extensão e Cultura, Florianópolis (SC), v. 2, n.1, jan./jun.2018. 
con ella dialogar, pero, ante todo, ser un elemento de construcción y transformación de la realidad regional.

Palabras clave: Extensión, Cultura, Recurso Financiero. 


\section{INTRODUÇÃO}

Com a publicação da Constituição Federal em 1988 vislumbrou-se de maneira efetiva, o reconhecimento oficial da importância da extensão universitária na formação acadêmica - sobretudo, dos alunos de graduação. No Artigo 207, a Constituição prescreve que "[...] as universidades gozam de autonomia didático-científica, administrativa e de gestão financeira e patrimonial e obedecerão ao princípio da indissociabilidade entre ensino, pesquisa e extensão (BRASIL, 1988). Nota-se, portanto, que o Ensino, a Pesquisa e a Extensão constituem os pilares básicos da Universidade. No que concerne à Extensão Universitária, Souza (2017) apresenta incisivas contribuições:

No tripé formado pelo ensino, pesquisa e extensão, o último apresenta
diferentes níveis de consolidação e institucionalização dentro das
universidades, muito em funça da complexidade representada pela
interdisciplinaridade, poder transformador da realidade, envolvimento de
diferentes atores sociais e impactos políticos sociais. Nesse contexto, a
extensão universitária ao longo das últimas décadas vem ganhando espaço e
importância nas instituições de ensino (SOUZA, 2017, p. 10)

Para compreender o que são, definitivamente, ações de extensão, é necessário pensá-las a partir de suas diretrizes: interação dialógica; interprofissionalidade e interdisciplinaridade; indissociabilidade entre ensino, pesquisa e extensão; impacto na formação do estudante e impacto social, como bem aponta a Política Nacional de Extensão Universitária, a qual foi elaborada durante o Fórum de Pró-Reitores de Extensão, em 2012.

Em síntese, cada uma dessas diretrizes entende as ações extensionistas da seguinte maneira: o princípio da "interação dialógica" entende que o desenvolvimento derelações entre Universidade e setores sociais deve ser marcado pelo diálogo e troca de saberes, substituindo o discurso da hegemonia acadêmica pela ideia de aliança com movimentos, setores e organizações sociais. A “interdisciplinaridade e interprofissionalidade", por sua vez, implica na necessidade de considerar, de forma integrada, os diversos conhecimentos desenvolvidos na universidade nas várias disciplinas e áreas do conhecimento, mediante a construção de alianças intersetoriais, interorganizacionais e interprofissionais.

No que tange à “[...] indissociabilidade do ensino-pesquisa-extensão", considerase que as ações de extensão adquirem maior efetividade se estiverem vinculadas ao processo de formação de pessoas (ensino) e de geração de conhecimento (pesquisa). Já o "impacto na formação do estudante" consiste no entendimento de que a extensão possibilita o enriquecimento da experiência discente em termos teóricos e metodológicos e, por isso, deve estar sustentada em iniciativas que viabilizem a flexibilização curricular 
e a integralização de créditos. Por fim, o “[...] princípio do impacto na transformação social' reafirma a Extensão Universitária como o mecanismo pelo qual se estabelece a inter-relação da Universidade com os outros setores da sociedade, com vistas a uma atuação transformadora, voltada aos interesses e necessidades da maioria da população, e propiciadora do desenvolvimento social e regional e de aprimoramento das políticas públicas" (FORPROEX, 2012).

Diante do exposto, vale ressaltar que A Universidade Estadual do Norte do Paraná (UENP) adota o mesmo conceito de extensão universitária definido pelo Fórum de PróReitores de Extensão das Instituições Públicas de Educação Superior Brasileiras ${ }^{1}$ : “A Extensão Universitária, sob o princípio constitucional da indissociabilidade entre ensino, pesquisa e extensão, é um processo interdisciplinar educativo, cultural, científico e político que promove a interação transformadora entre universidade e outros setores da sociedade" (FORPROEX, 2012).

A política institucional de extensão deve ser capaz de oportunizar condições e contribuir especificamente para o desenvolvimento das atividades do ensino e de pesquisa; propiciar uma abordagem multidisciplinar e interdisciplinar; promover a articulação da universidade com a comunidade e seus segmentos significativos. É importante ter clareza de que não é apenas sobre a sociedade que se almeja produzir impacto e transformação com a Extensão Universitária, mas a visão da UENP, enquanto parte da sociedade, deve também sofrer impacto, ser transformada. Disponibilizando ao público externo o conhecimento adquirido com o ensino e a pesquisa desenvolvidos na Universidade, a extensão se consolida na mesma medida em que a universidade aprende com a comunidade. Compreende-se, assim, a extensão como via de mão dupla: ao mesmo tempo em que se ensina, se aprende, produzindo conhecimento, conforme aponta o Plano de Desenvolvimento Institucional da UENP (PARANÁ, 2018).

Em suma, as ações de extensão contribuem para o crescimento e transformação da comunidade acadêmica e comunidade externa. Nessa perspectiva, este artigo tem

\footnotetext{
${ }^{1}$ O Fórum de Pró-reitores de Extensão (FORPROEX) tem como objetivo principal a articulação e definição de políticas extensionistas, estratégias para a sua institucionalização e implantação de um sistema de monitoramento e avaliação. Assim, o FORPROEX tem um papel fundamental no processo de consolidação e institucionalização da extensão universitária dentro das universidades.
} 
como objetivo apresentar as ações de extensão e cultura desenvolvidas pela UENP, bem como suas respectivas fontes de financiamento nos anos de 2014 a 2017.

\section{METODOLOGIA}

Este artigo contém informações quantitativas referentes às ações de extensão levantadas por meio do Sistema de Registro de Atividades de Pesquisa, Ensino e Extensão - SECAPEE - sistema utilizado na UENP. As ações culturais foram levantadas por meio dos registros das atividades que se encontram junto à Pró-Reitoria de Extensão e Cultura (PROEC). Já as informações concernentes aos recursos financeiros foram mobilizadas através de relatórios fornecidos pela Pró-Reitoria de Administração e Finanças (PROAF).

\section{Extensão em números: quantidade e qualidade}

A Universidade Estadual do Norte do Paraná foi criada em 2006 pela Lei ${ }^{\circ}$ 15.300/2006. Com sede na cidade de Jacarezinho, Paraná, a UENP possui campi nos municípios de Bandeirantes, Cornélio Procópio e Jacarezinho, ou seja, a Universidade está situada na mesorregião Norte do Estado do Paraná - popularmente conhecida como Norte Pioneiro. Esta região, vale frisar, é constituída por uma população que concentra em sua rede de municípios cerca de 600 mil habitantes, o que corresponde a $5 \%$ da população paranaense.

Fontes oficiais do governo do Estado do Paraná atestam que o Índice de Desenvolvimento Humano da região do Norte Pioneiro encontra-se abaixo da média do Estado. Isto porque dados negativos como o alto número de mortalidade infantil, bem como a baixa taxa de frequência escolar somam-se às atividades agrícolas e industriais com pouca capacidade de agregação de valor. Por esta e outras razões socioeconômicas e culturais, a região do Norte Pioneiro do Paraná já foi, inclusive, (re)conhecida como "Ramal da Fome".

Circunscrita, portanto, em meio a este cenário de subdesenvolvimento, a UENP tem por objetivo primeiro ser protagonista na produção do conhecimento científico em suas mais diversas formas. A isto, soma-se o desejo institucional de contribuir com o desenvolvimento da região, com vistas a participação ativa nos municípios de sua abrangência por meio de projetos de extensão universitária. Nessa perspectiva, é importante quantificar os programas e projetos realizados pela Universidade entre os anos de 2014 e 2017. Em 2014, 70 ações de extensão atenderam a comunidade externa. Em 2015, a Universidade ofereceu à comunidade regional 64 programas/projetos, enquanto 
que, em 2016, 59 ações de extensão aconteceram em alguns municípios de sua abrangência, conforme ilustra a Figura 1.

Figura 1: Projetos/Programas de extensão registrados e executados na UENP entre 2014 e 2017.

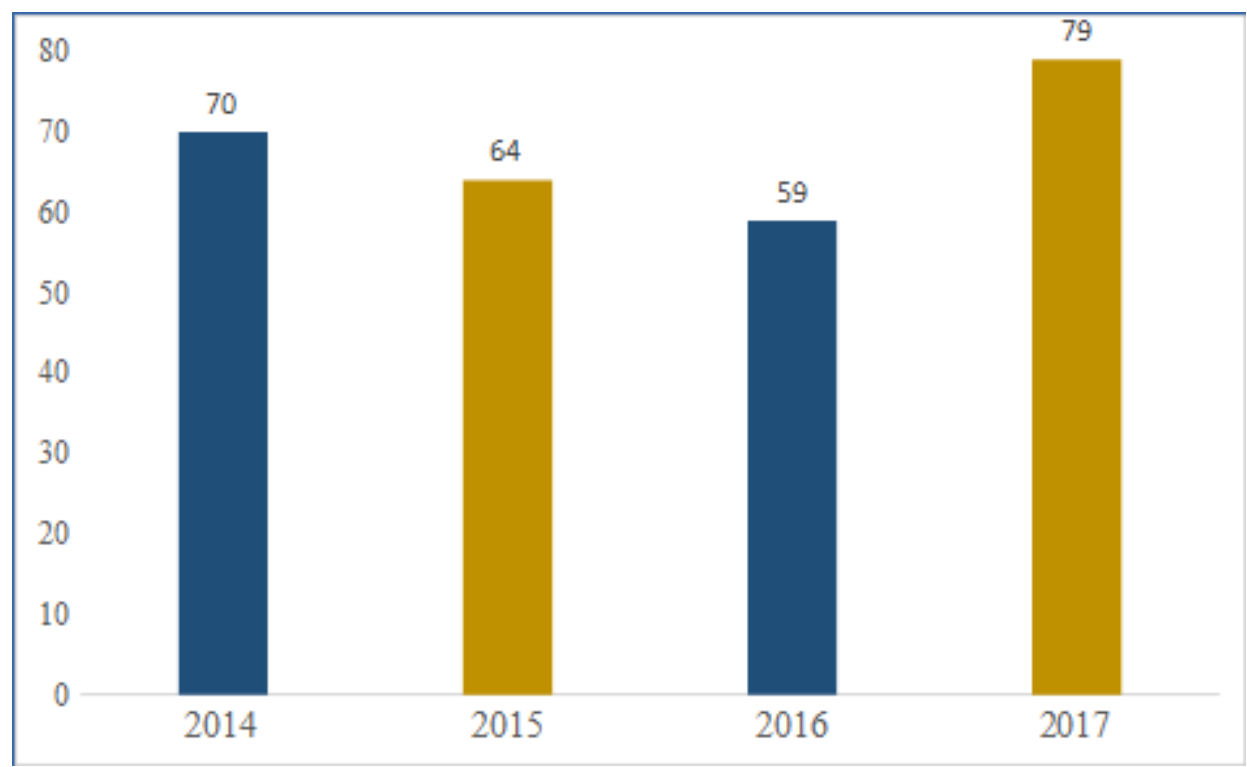

Fonte: Dados da Pesquisa (2018).

Conforme se observa, os projetos/programas de extensão na UENP diminuíram nos anos de 2014 a 2016 voltando a aumentar em 2017. Estas oscilações podem ser explicadas por diversas razões, dentre elas, o licenciamento dos docentes para aperfeiçoamento profissional, ausência de editais de financiamento etc.

No que tange aos eventos de extensão realizados pela Universidade Estadual do Norte do Paraná, é possível constatar, por meio da Figura 2, um aumento progressivo dessas ações, que aconteceram nos três campi da Instituição. 
Figura 2: Eventos de extensão registrados e executados na UENP entre 2014 e 2017.

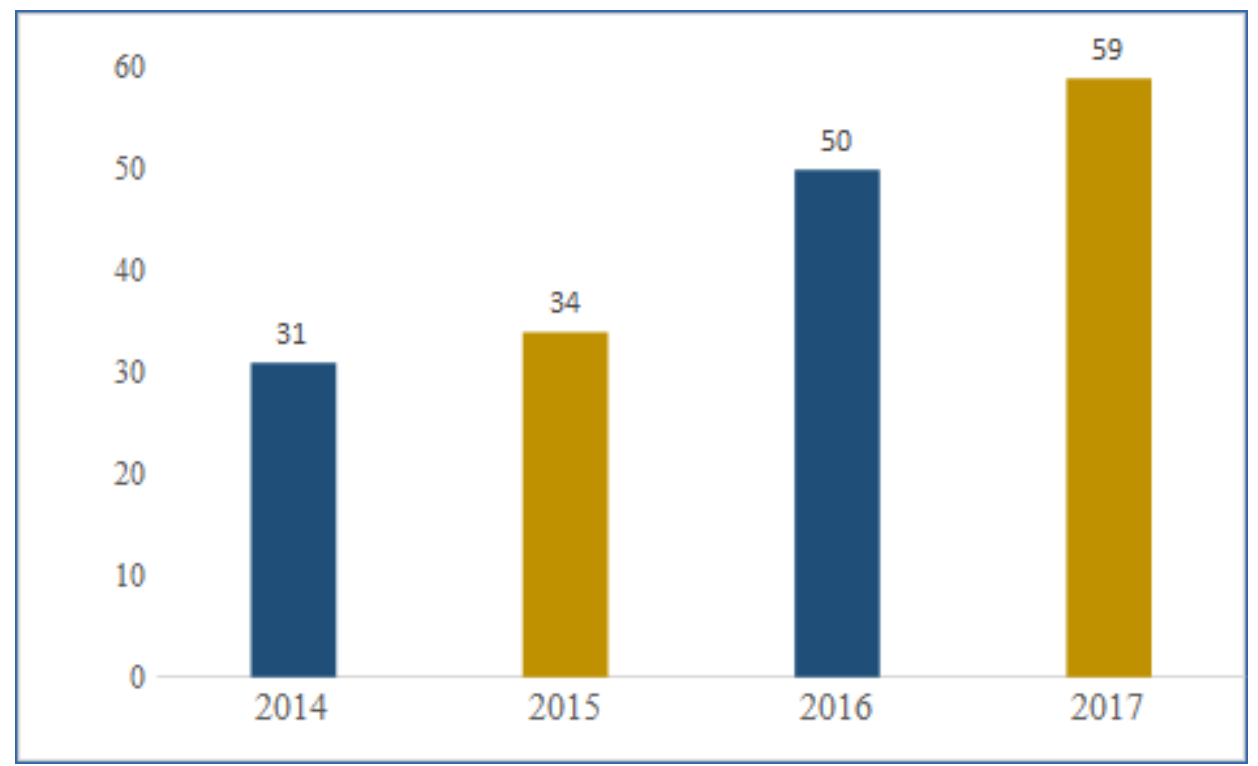

Fonte: Dados da Pesquisa (2018)

Os eventos de extensão são, recorrentemente, organizados por docentes dos cursos de graduação. Tendo como primícias as produções científicas, tais eventos, quando não discutem abertamente questões concernentes aos problemas de ordem social, acabampor atrair, para os espaços da Universidade, agentes sociais que contribuem, de maneira profícua, com a discussão proposta. É justamente nesse contexto que observa, clarividentemente, a indissociabilidade do Ensino, da Pesquisa e da Extensão, que, aliás, contempla outra vertente: os cursos de extensão, os quais foram realizados na UENP durante o período recortado para discussão (Figura 3). 
Figura 3: Cursos de extensão registrados e executados na UENP entre 2014 e 2017.

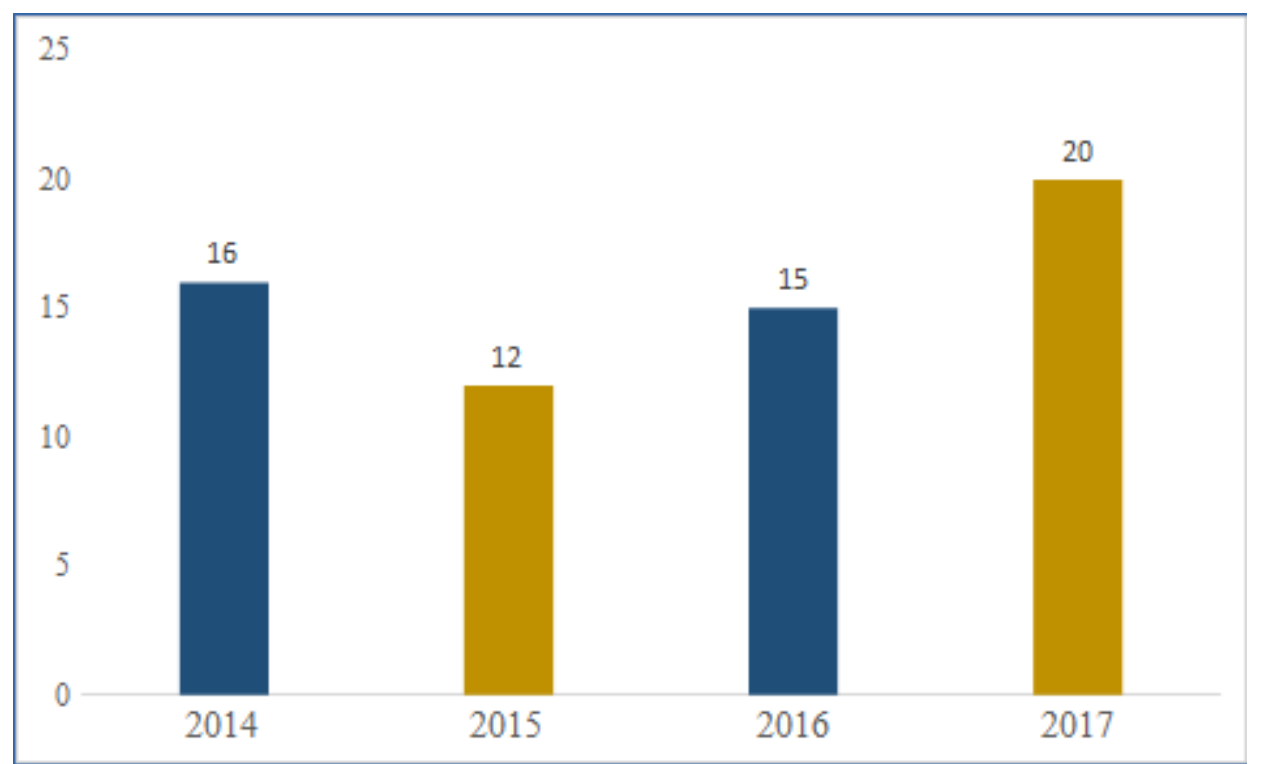

Fonte: Dados da Pesquisa (2018).

Na Figura 3, observa-se que os cursos de extensão ofertados pela UENP entre 2014 e 2017 também sofreram uma oscilação. Esses cursos, que também são ofertados por docentes que ministram aulas na graduação, tem por objetivo atender as demandas da sociedade e, via de regra, necessidades educacionais - sobretudo, no caso da UENP, em que a maior parte dos cursos (de graduação) ofertados são voltados para as licenciaturas.

A Universidade Estadual do Norte do Paraná é uma universidade relativamente nova. Desde a sua criação, em 2006, são apenas 12 anos de existência. De 2014 a 2017 período elegido para relatar as ações extensionistas, nota-se, no entanto, que a UENP tem avançado - e muito - na sua política de extensão universitária, uma vez que, neste período o Sistema e Registro de Atividades de Pesquisa, Ensino e Extensão - (SECAPEE) registou, entre cursos, programas e projetos, 509 ações de extensão.

Os números expostos atestam o compromisso da UENP com a extensão universitária. Fato este constatado por meio de ações de professores, alunos, agentes universitários e, também, da administração da Universidade, os quais, em 2017, promoveram, junto às Instituições de Ensino Superior do Paraná, uma edição regional do Projeto Rondon. Na ocasião, a UENP e as universidades parceiras realizaram nos municípios do Norte Pioneiro, mais de 30 mil atendimentos à população. 


\section{Fomento à extensão: bolsa e custeio de projetos}

Em relação ao financiamento dos programas, projetos e eventos de extensão na UENP, vale considerar que algumas agências de fomento como Fundação Araucária, Fundo Paraná, Ministério da Educação e Ministério do Esporte viabilizam, financeiramente, a presença da Universidade em ações junto à comunidade externa.

A Fundação Araucária de Apoio ao Desenvolvimento Científico e Tecnológico do Estado do Paraná (FA) é um órgão de fomento e busca o desenvolvimento social, econômico e ambiental do Estado do Paraná, por meio de investimentos em ciência, tecnologia e inovação. A FA é uma das 26 Fundações Estaduais de Amparo à Pesquisa do Brasil e faz parte do Conselho Nacional das Fundações de Amparo à Pesquisa (Confap). Desde o ano de 2014, tem financiado bolsas de extensão universitária por meio do Programa Institucional de Bolsas para Extensão Universitária (PIBEX). O programa destina-se a concessão de bolsas a alunos regularmente matriculados em cursos de graduação das instituições de ensino superior do Paraná, para desenvolvimento de atividades vinculadas à extensão universitária. A UENP foi contemplada com 24 bolsas em 2014 e 2015, 23 em 2016 e 2017.

Outra fonte de recurso das ações de extensão na UENP é o Fundo Paraná. Criado pela Lei $\mathrm{n}^{\mathrm{o}} 12.020 / 98$ e alterado pela Lei $\mathrm{n}^{\circ} 15.123 / 06$ para atender ao estabelecido no Art. 205 da Constituição Estadual o Fundo apoia o desenvolvimento científico e tecnológico do Estado do Paraná, com o financiamento de programas e projetos de pesquisas institucionais, bem como os chamados projetos e programas estratégicos. $\mathrm{Na}$ UENP, alguns programas são financiados por este fundo, tais como: o Bom Negócio Paraná; o Núcleo de Estudos e Defesa de Direitos da Infância e da Juventude (NEDDIJ); o PATRONATO; o Núcleo Maria da Penha (NUMAPE) e os subprogramas denominados Programa Universidade Sem Fronteiras (Educação, Promoção da Saúde, Agricultura Familiar e Agroecologia, Inovação e Diversidade Cultural, Inclusão e Direitos Sociais).

O Programa de Extensão Universitária (ProExt), do governo federal, tem o objetivo de apoiar as instituições públicas de ensino superior no desenvolvimento de programas ou projetos de extensão que contribuam para a implementação de políticas públicas. No último edital a UENP enviou 26 propostas sendo contemplada com apenas 01 programa, o que, de certa forma, inviabilizou uma quantidade significativa de alunos, professores e agentes universitários atuando de maneira incisiva e direta na comunidade externa.

Os resultados do ProExt contribuíram para o fortalecimento e consolidação da 
política de extensão na Universidade, mas, infelizmente, não se pode contar com novos editais e nem perspectivas de lançamento. Em entrevista à revista Brasileira de Extensão Universitária, a pró-reitora de extensão da Universidade Federal do Rio Grandes do Sul (UFRGS) professora Sandra de Deus destaca sobre o PROEXT: “Neste momento, só posso lamentar que não tenha sido priorizado pelo MEC um programa tão importante. Reconheço a crise econômica, mas é neste momento que se define o que é e o que não é prioridade" (DEUS, 2017).

Recentemente, a UENP foi contemplada com uma aprovação no programa PARADESPORTO, do Ministério da Cultura. O referido programa tem como objetivo geral democratizar o acesso à prática e à cultura do esporte educacional prioritariamente das pessoas com deficiência e que se encontram em áreas de vulnerabilidade social. Este projeto é financiado pelo Ministério do Esporte. Nessa mesma perspectiva de financiamento, o Ministério da Educação (MEC) possui o Programa de Educação Tutorial (PET), que, em sua essência, desenvolve ações de ensino, pesquisa e extensão. A UENP foi contemplada com um projeto desde 2010, na área de Biologia.

Podemos afirmar que, de modo geral, as agências de fomento vinculadas ao governo do Paraná são as principais financiadoras da extensão universitária no Estado e, também, na UENP. O quadro abaixo ilustra, ainda que sinteticamente, as formas pelas quais os recursos são distribuídos para viabilização das ações de extensão, ou seja, os recursos são mobilizados em formas de bolsas para alunos de graduação, profissional recém-formado, orientadores; e, por outra via, para custeio/capital dos programas/projetos. 
Quadro 1: Recursos vigentes destinados a ações de extensão na UENP

\begin{tabular}{|c|c|c|c|c|}
\hline Ação & Distribuição bolsas & Total de bolsas & Custeio/Capital & $\begin{array}{ll}\text { Total } & \text { do } \\
\text { recurso } & \end{array}$ \\
\hline PIBEX & 23- Graduandos & $110.400,00$ & - & $110.400,00$ \\
\hline Bom Negócio Paraná & $\begin{array}{l}\text { 3- } \mathrm{RF}^{*} \\
\text { 3- Graduandos } \\
\text { 2- Orientadores }\end{array}$ & $115.305,00$ & $40.000,00$ & $155.305,00$ \\
\hline NEDDIJ & $\begin{array}{l}\text { 4- RF } \\
\text { 5- Graduandos } \\
\text { 2- Orientadores }\end{array}$ & $165.420,00$ & $7.000,00$ & $172.400,00$ \\
\hline PATRONATO 1 & $\begin{array}{l}\text { 4- RF } \\
\text { 6- Graduandos } \\
\text { 5- Orientadores }\end{array}$ & $211.400,00$ & $10.000,00$ & $221.400,00$ \\
\hline PATRONATO 2 & $\begin{array}{l}\text { 4- RF } \\
\text { 6- Graduandos } \\
\text { 5- Orientadores }\end{array}$ & $211.400,00$ & $10.000,00$ & $221.400,00$ \\
\hline NUMAPE & $\begin{array}{l}\text { 3- RF } \\
\text { 3- Graduandos } \\
\text { 2- Orientadores }\end{array}$ & $114.600,00$ & $7.000,00$ & $121.600,00$ \\
\hline USF (9) & $\begin{array}{l}\text { 18- RF } \\
\text { 9- Graduandos } \\
\text { 9- Orientadores }\end{array}$ & $623.700,00$ & $118.800,00$ & $\begin{array}{l}82.500,00 \text { cada } \\
(742.500,00)\end{array}$ \\
\hline PROEXT (MEC) & 12- Graduandos & $103.680,00$ & $196.620,00$ & $300.000,00$ \\
\hline PET (MEC) & $\begin{array}{l}\text { 12-Graduandos } \\
\text { 1- Orientador }\end{array}$ & $84.000,00$ & $4.800,00$ & $88.800,00$ \\
\hline Paradesporto (ME) & $\begin{array}{l}\text { 4- Graduandos } \\
\text { 1- Orientador }\end{array}$ & $131.062,00$ & $21.000,00$ & $152.062,00$ \\
\hline Total & $\begin{array}{l}\text { 83- Graduandos } \\
\text { 36- RF } \\
\text { 26- Orientadores }\end{array}$ & $1.870 .967,00$ & $415.220,00$ & $2.286 .187,00$ \\
\hline
\end{tabular}

Fonte: Dados da Pesquisa (2018).

*RF- recém-formado

Em suma, entende-se que o investimento na área da extensão é essencial para se alcançar o previsto constitucionalmente, garantindo o princípio da indissociabilidade entre ensino, pesquisa e extensão. Portanto, os números apresentados até o presente momento demonstram o quanto a Universidade Estadual do Norte do Paraná tem avançado em termos extensão universitária. Por outra via, entretanto, os números também apontam que fontes de financiamentos vinculados ao governo federal não chegam às UENP na mesma densidade que as agências paranaenses.

Tal fato pressupõe a hipótese de que o governo federal tem tido dificuldade em mobilizar recursos financeiros para viabilizar ações de extensão em todo território nacional. O PROEX, a exemplo, é um dos programas que afetam, diretamente, o trabalho 
da UENP da comunidade externa com ações de maior envergadura, uma vez que o orçamento do referido programa possibilita a realização de programas e projetos de maior impacto.

Enquanto o governo federal não aprimora ou mobiliza recursos financeiros por meio de editais de fomento à extensão universitária, a UENP tem contado com as agências de fomentos do Estado do Paraná e, também, com parcerias junto à iniciativa privada que tem financiado, inclusive, ações culturais, as quais, por sua vez, não contam com nenhum incentivo federal, estadual ou municipal. O próximo e último tópico versará sobre o modo com a UENP tem realizado seus projetos culturais.

\section{Ações culturais em perspectiva: diálogo entre universidade e sociedade}

Como foi possível observar anteriormente, os programas dos governos federal e estadual publicam editais para destinados aos projetos de extensão. Os dados apresentados acima atestam a participação efetiva da Universidade Estadual do Norte do Paraná no que tange à submissão de propostas, visto que ela, por diversas vezes, foi e continua tendo seus projetos aprovados. Ainda que tais editais de financiamento apresentam lacunas consideráveis para esses projetos, a extensão universitária na UENP está em pleno processo de consolidação dadas as cifras que mantém as ações deextensão em todos os campi.

Por outra via, entretanto, as ações culturais desta Universidade não contam com recursos financeiros provenientes de programas governamentais como os que viabilizam os projetos extensionistas, por exemplo. Ainda que os professores tenham a possibilidade de submeter propostas culturais nos projetos de extensão, vale ressaltar que este número, quando aprovado, é diminuto. Este cenário adverso somado a não existência de cursos de graduação voltado às Artes (de modo geral) constituem os desafios da UENP no trato com uma das áreas primordiais para o desenvolvimento e/ou aperfeiçoamento da sensibilidade estética do sujeito: a cultura.

Diante do cenário, brevemente arrolado, a Pró-Reitoria de Extensão e Cultura, por meio da Diretoria de Cultura, assumiu o protagonismo na articulação de ações culturais dentro e fora dos espaços da Universidade. Desse modo, vale frisar que PROEC tem buscado estabelecer parcerias diretas com a comunidade artística local e regional, de modo a concretizar o diálogo entre a cultura e os demais saberes circunscritos nas esferas universitária e comunitária. Este processo se deu e se dá através de debates cuja finalidade reside em discutir questões teóricas e práticas relacionadas à preservação, restauração e 
salvaguarda de bens patrimoniais e de bens artísticos das cidades onde estão instalados seus campi e entorno.

A UENP tem apoiado iniciativas que visam à realização de atividades expositivas dos museus em funcionamento em sua região de abrangência e a promoção de eventos de natureza científica, como o Seminário Interdisciplinar de Memória, que tem por finalidade conscientizar a comunidade acadêmica e a comunidade externa no que se refere à preservação de seu patrimônio, levando-os a se apropriar e a usufruir dos bens e valores que os constituem. É nesse sentido que a UENP cumpre sua função enquanto instituição consciente do valor histórico de sua região.

A democratização dos meios de produção e difusão artística é, também, um dos pilares da Cultura da Universidade. Eventos culturais como a "Mostra de Artes Plásticas da UENP", o "Salão de Artes de Jacarezinho", a mostra de teatro "EnCena", o "Café Cultural", a "Estação Literatura", o "Colóquio de Cultura Afro-brasileira" e as "Oficinas de Teatro" e de "Mandalas", exemplificam um pouco desse movimento cultural na Universidade. Esses eventos articulam a integração entre os campi e a população local, confirmando, assim, o comprometimento da UENP com as ações de acolhimento e respeito à diversidade cultural.

Não obstante, o fomento às ações já existentes na Universidade tem sido umadas prioridades da PROEC, que tem incentivado as manifestações culturais de seus alunos, apoiando, institucionalmente, projetos como a Bateria Capiau, do curso de Direito, e acolhendo eventos como a Semana Internacional dos Museus. Além dos muros, a UENP tem trabalho ainda em projetos de tombamentos de bens de valor histórico, cultural, arquivístico, bibliográfico, artístico e arquitetônico, e realizado mapeamento cultural, buscando identificar as potencialidades e vocações culturais da região. A UENP, através da PROEC, estabelece, ainda, parcerias estratégicas com entidades públicas e privadas para efetivação de suas ações e incentiva seus docentes a submeterem projetos voltados à área da cultura em diversos programas institucionais, como o Universidade Sem Fronteiras, PIBEX, além dos editais do Ministério da Cultura.

Mais do que promover eventos artístico-culturais, a UENP acredita no conceito de Cultura, que, em sua dimensão transversal, abrange todas as realizações materiais e imateriais de um povo, nesse caso, da população do norte do Paraná. Daí a justificativa para um trabalho insistente no fomento, na inserção e na reflexão de sua realidade local, com vistas à tomada de consciência de sua comunidade (acadêmica e externa) em relação 
aos aspectos que demarcam sua identidade. Em números, a PROEC, entre 2014 e 2017 realizou as seguintes atividades:

Quadro 2: Ações culturais realizadas pela PROEC de 2014 a 2017.

\begin{tabular}{|l|c|}
\hline Ações Culturais: 2014 a 2017 & Quantidade \\
\hline Colóquios e Seminários & 4 \\
\hline Exposições de Artes e Literárias & 10 \\
\hline Mostra de Artes Cênicas & 4 \\
\hline Café Cultural & 2 \\
\hline Projetos Internacionais (Intercâmbio Cultural das Artes) & 1 \\
\hline Oficinas Culturais & 4 \\
\hline Mostras e Recitais Musicais & 2 \\
\hline Agendamento de Apresentações (eventos) & 10 \\
\hline Apoio Cultural Interinstitucional & 6 \\
\hline Apoio Cultural Institucional & 8 \\
\hline Aprovação de Projeto - Lei de Incentivo & 1 \\
\hline Projeto Cultural Institucional (UENP Talentos) & 1 \\
\hline Total & $\mathbf{5 3}$ \\
\hline
\end{tabular}

Fonte: Dados da pesquisa (2018).

As ações de cultura expressas no Quadro 2 foram realizadas, em parte, com recursos próprios. Faz-se necessário ressaltar, que, por outro lado, as atividades culturais contaram com expressivo apoio da comunidade externa. Em outras palavras, artistas e agentes culturais promoveram exposições, mostras e oficinas voluntariamente, uma vez que entenderam a situação econômica da Pró-Reitoria de Extensão e Cultura que, por sua vez, não dispõe de orçamento próprio (institucional) para o financiamento de suas próprias ações.

Nesse viés, é importante frisar que muitos artistas, embora tivessem uma obra já construída e estabelecida, não eram (re)conhecidos no âmbito da comunidade acadêmica e, até mesmo, na comunidade externa. Nesse sentido, entende-se que a Universidade contribuiu, assiduamente, com a divulgação do trabalho desses agentes culturais, uma vez que chancelou, por meio de exposições, a qualidade e o valor artístico de cada um deles. Fato este comprovado por meio das 10 mostras de artes visuais realizadas nos espaços da UENP, nas cidades onde estão instalados seus campi (Bandeirantes-PR, Cornélio 
Procópio-PR e Jacarezinho-PR), e, até mesmo, em uma universidade estrangeira, como foi o caso da Universidad Nacional de Itapúa (UNI), no Paraguai. Nesta ocasião, 10 artistas do Norte Pioneiro do Paraná tiveram a oportunidade inédita de encaminhar suas obras de arte para exposição de curta duração na UNI.

\section{Extensão e Cultura na UENP: perspectivas para o futuro}

A Universidade Estadual do Norte do Paraná é uma instituição comprometida com o desenvolvimento da Extensão e da Cultura. Por isso, pretende, em médio prazo, aprimorar suas políticas institucionais com objetivo de ofertar, à comunidade acadêmica e à comunidade externa, ações, programas e projetos de qualidade. Para tanto, a PróReitoria de Extensão e Cultura (PROEC) pretende criar, até 2022, o Plano de Cultura da UENP, que, além de regulamentar as ações culturais no âmbito da Universidade, garantirá $\mathrm{o}$ acesso aos editais de fomento à cultura oriundos do Governo Federal e de outras fontes de financiamento. De igual modo, pretende-se, até 2022, criar o regulamento de normatização de eventos de extensão, criar o manual de extensão e cultura e revisar os regulamentos já existentes e elaborar novos documentos para normatizar as ações de extensão. Na mesma esteira, pretende-se criar o sistema para geração de certificado e aperfeiçoar o sistema de gestão de projetos e programas de extensão, com intuito de aperfeiçoar e acelerar tais procedimentos administrativos.

Até 2022, a PROEC visa criar o Fundo de Extensão e Cultura, com vistas ao recebimento de recursos financeiros oriundos dos mecanismos de Incentivo Fiscal, que, por meio de instituições privadas, poderão viabilizar as ações de extensão com viés cultural. Com esses e outros recursos institucionais, pretende-se ofertar bolsas institucionais de extensão, ampliar o número de projetos de extensão, aumentar o número de servidores da PROEC e fomentar atividades artísticas, culturais e esportivas em todos os campi da UENP. Pretende-se, ainda, incentivar a participação de agentes universitários em ações de extensão, firmar novas parcerias com instituições públicas e privadas com a finalidade de consolidar e ampliar as ações extensionistas. Construído todo esse cenário, a PROEC irá impactar a avaliação do corpo docente com indicadores acadêmicos de extensão.

Nesse viés, há, também, a pretensão de assegurar a inserção de ações extensionistas nas grades curriculares dos cursos de graduação, conforme disposto na meta 12 do plano nacional de educação e realizar o II Fórum de Extensão e Cultura, com intuito de se debater e avaliar a situação da extensão e da culturanessa Instituição. Como 
se observa, a proposta de desenvolvimento da área de extensão, é buscar cada vez mais a sua consolidação, tanto na proposição de promover a interação da UENP com a comunidade externa, quanto de fortalecer o ensino e pesquisa. A participação efetiva de estudantes e professores em ações de extensão contribuem para o desenvolvimento social e é um dos papéis essenciais da universidade.

No âmbito da cultura, a PROEC, preocupada com a manutenção de seu acervo cultural, pretende levantar informações sobre os monumentos históricos e artísticos adjacentes à UENP e revitalizá-los quando necessários. Pretende-se, ainda, instituir uma agenda cultural no site da UENP; criar uma incubadora de artistas e projetos culturais; e intensificar as ações que visam a democratização de acesso aos bens culturais nos espaços da Universidade. Para tanto, será necessária a construção de espaços específicos para ações culturais, tais como teatro, sala de exposição, museu etc. Nesse mesmo sentido, pretende criar ambientes culturais aproveitando espaços da UENP que, porventura, estejam ociosos; e, também, construir espaços de convivência com intuito de que a comunidade acadêmica possa congregar-se e compartilhar experiências acadêmicas e culturais.

\section{CONSIDERAÇÕES FINAIS}

Diante do exposto, ficou claro e evidente que a UENP e a sociedade possuem vínculos viscerais. Por isso, a Instituição tem ido não apenas ao encontro das demandas da sociedade, mas, e, sobretudo, tem dialogado com ela. $\mathrm{O}$ resultado disso é a gradativa transformação social que a Universidade tem aferido a região do Norte Pioneiro do Paraná, que, como exposto anteriormente, já foi conhecida como ramal da fome. Assim, é possível considerar que a UENP, no âmbito da extensão, está pronta para enfrentar os desafios que lhes são interpostos - desafios estes, aliás, que são de naturezas diversas, como ausência de programas consistentes e não aprimorados pelo governo federal, como o PROEXT, por exemplo; e, também, editais e programas específicos para ações culturais que são partes indissociáveis da extensão universitária.

Enquanto os recursos financeiros não aportam na Universidade Estadual do Norte do Paraná de modo a contribuir e atender as demandas da extensão universitária, a PróReitoria de Extensão e Cultura tem trabalhado de maneira assídua para que a submissão de programas e projetos dos professores universitários sejam efetivados nos editais abertos pelas agências de fomento. Para além da obrigação iminente de operacionalizar 
essas propostas, a UENP entende que o tripé Ensino, Pesquisa e Extensão constitui a máxima para o saudável desenvolvimento da Universidade e, sobretudo, da sociedade na qual está inserida. 


\section{REFERÊNCIAS}

BRASIL. Constituição da República Federativa do Brasil de 1988. Brasília: Senado Federal, p.123, 1988.

DEUS, S. Entrevista: A valorização da extensão universitária no Brasil. Revista Brasileira de Extensão Universitária, v. 8, n. 2, p. 121-124, 2017.

Fórum de Pró-Reitores de Extensão das Universidades Públicas Brasileiras. Política Nacional de Extensão Universitária. Manaus, 2012.

PARANÁ, U, E, N. Plano de Desenvolvimento Institucional (PDI) UENP. Jacarezinho, 2017.

SOUZA, Roberto Eduardo Santos. Caminhos para a construção de uma sistemática de avaliação dos projetos de extensão da Escola de Governo da Fundação João Pinheiro. Monografia (Especialização em Administração Pública) - Fundação João Pinheiro, Escola de Governo Professor Paulo Neves de Carvalho. Belo Horizonte, p. 10, 2017. $66 \mathrm{f}$. 